\title{
Fc-Epsilon Receptor (CD23) Expressing Follicular Dendritic Cells as a Main Prognostic Factor in Follicular Lymphoma
}

\author{
Natalia A. Falaleeva, Eugeny A. Osmanov, Nikolay N. Tupitsyn* \\ Federal State Budgetary Institute N. N. Blokhin Russian Cancer Research Center, Health Ministry of Russian Federation, Moscow, \\ Russia \\ Email: ${ }^{*}$ ntca@yahoo.com
}

How to cite this paper: Falaleeva, N.A., Osmanov, E.A. and Tupitsyn, N.N. (2017) Fc-Epsilon Receptor (CD23) Expressing Follicular Dendritic Cells as a Main Prognostic Factor in Follicular Lymphoma. Advances in Biological Chemistry, 7, 107121.

https://doi.org/10.4236/abc.2017.72007

Received: February 11, 2017

Accepted: April 22, 2017

Published: April 25, 2017

Copyright (c) 2017 by authors and Scientific Research Publishing Inc. This work is licensed under the Creative Commons Attribution International License (CC BY 4.0).

http://creativecommons.org/licenses/by/4.0/

\begin{abstract}
Fc-epsilon receptor (CD23)-expressing follicular dendritic cells is a main prognostic factor in follicular lymphoma. Falaleeva N. A., Osmanov E. A., Tupitsyn N. N. Federal State Budgetary Institute N. N. Blokhin Russian Cancer Research Center, Health Ministry of Russian Federation, Moscow, Russia SUMMARY Follicular dendritic cells, expressing FceRII or CD23 (FceRIIFDCs) as a component of non-tumor environment have been studied in 232 follicular lymphoma (FL) patients. FceRIIFDCs were found in $87.5 \%$ of follicular lymphoma cases and were associated with a nodular pattern of tumor growth $(\mathrm{p}=0.000)$, but not the cytological grade of lymphoma. There were no associations of FceRIIFDC with clinical prognostic factors (FLIPI indices) or with bone marrow involvement in FL patients by histology. The presence of FceRIIFDCs in tumor tissue was an independent prognostic factor according to treatment results, i.e. frequency of CR, duration of OS and PFS. Bone marrow involvement significantly worsened the prognosis in FceRIIFDC-positive group of patients. We suggest a new prognostic index (FDC-IP) that allows biochemical identification of the following patient groups: FceRIIFDC-positive patients without bone marrow involvement (good prognosis), FceRIIFDC-positive patients with bone marrow involvement (intermediate prognosis), FceRIIFDC-negative patients (poor prognosis). These 3 groups significantly differ $(\mathrm{p}=0.000)$ both in OS and in PFS. This is the first evidence of the possibility to assess tumor behavior and treatment results in FL according to lymphoma biochemical and other than clinical parameters.
\end{abstract}

\section{Keywords}

Follicular Lymphoma, CD23-Positive Follicular Dendritic Cells, Prognosis 


\section{Introduction}

Follicular lymphoma (FL) is a most frequent hemopoietic tumor in adults. It is characterized by an indolent course and a rather favorable outcome. However, in some cases the tumor fails to respond to therapy, and demonstrates resistance, rapid recurrence and has a fatal outcome.

FL prognostic patterns are based on international prognostic indices (IPI) including FL specific FLIPI-1 and -2. These indices take into account degree of lymph node and bone marrow involvement, the presence and number of extranodal sites, anemia, increased serum lactate dehydrogenase levels and advanced age in some of them. Basing on the indices the patients are divided into risk groups and receive treatment accordingly [1]. Over the last 15 years, the treatment has included monoclonal antibody to $\mathrm{CD} 20$ as a mandatory component.

Choice of treatment policy is mainly based on the prognostic indices and morphological findings which distinguish tumors with different cellular content (as required by the $2008 \mathrm{WHO}$ classification), growth pattern and proliferative activity. Mandatory criteria include confirmed mature B-cell nature of the tumor, CD20 expression, and if needing additional markers (bcl-2, bcl-6, MUM1), B-cell clonality and other criteria are used.

FL originates from immunity cells, peripheral B-lymphocytes of lymph node follicular centers. These cells are referred to as centroblasts and centrocytes. As a whole the tumor content is polymorphous with T-cells, macrophages, follicular dendritic cells (FDCs) found within malignant germinal centers besides B-cells.

At the beginning of the 21st century the investigators paid attention to the fact that this hemopoietic tissue tumor was in many respects regulated by cells of so called non-tumor environment, i.e. T-lymphocytes and macrophages [2]. Infiltration of tumor tissue by immune cells was reflected by gene expression profiles in the tumor tissue. Two types of immune response were defined accordingly that were associated with microenvironment cells infiltrating the tumor. Type 1 immune response was due to T-lymphocytes and had a good prognosis. While immune response type 2 was associated with macrophages and poor prognosis. It was shown later that implementation of immune response in germinal centers involves (besides T-helpers, follicular T-helpers) T-regulatory cells that could produce a positive effect in FL owing to specific features of the regulation or B-cell response. While macrophages had a reverse effect, that was counteracted by rituximab. Assessment of gene expression profiles was not widely used in clinical practice because the procedure was too labor-consuming, and surrogate markers of microenvironment were not utilized due to poor data reproducibility and not clear clinical significance.

This paper evaluates the role of non-tumor microenvironment in FL that is FDCs expressing Fc-epsilon receptor II referred to as CD23 according to the differentiation antigen nomenclature.

\section{Materials and Methods}

The investigation was made at the N. N. Blokhin Russian Cancer Research Cen- 
ter, RF Ministry of Health.

A total of $232 \mathrm{FL}$ patients ( 87 males and 145 females) were included in retrospective analysis. All patients were examined, managed and received treatment or treatment recommendations at the Hematology Malignancy Chemotherapy Department during January 1989 through January 2016.

FL morphological diagnosis was made at the Human Tumor Pathology Department, Clinical Oncology Research Institute, N. N. Blokhin Russian Cancer Research Center, basing on tumor tissue histology according to the World Health Organization hemopoietic and lymphoid tissue tumor classification [3]. Tumor cell immunohistochemical analysis to define non-Hodgkin's lymphoma type was made basing on the WHO 2008 classification. The diagnosis of all patients including those who were studied before 2008 was done according WHO 2008 classification.

Immunophenotyping of biopsy cells from extramedullary tumors was made using immunofluorescent staining of fresh frozen sections. Since the study took more than two decades the monoclonal antibody panel was continually supplemented with and always included antibodies to B-cell antigens (CD19, CD20, CD21, CD22, CD23 immunoglobulins), T-lineage antigens (CD3, CD4, CD5, CD7, CD8), histiocyte and macrophage antigens (CD163), non-lineage antigens CD10, CD38, HLA-DR, common leukocyte antigen CD45 and Ki-1 (CD30) molecule. CD23 detection used standard monoclonal antibodies for by enzyme immunoassay in paraffin blocks, and CD23 pure, Clone M-L233, BD Biosciences, USA, with goat anti-mouse Ig-FITC, BD Biosciences, USA, for immunofluorescent staining of tumor sections. Reactivity was detected using an Axioplan-2 luminescent microscope, $\times 40$.

Immunological study of bone marrow puncture biopsy cells was made by flow cytometry using FACScan or FACSCANTO II. Three-color and multi-color fluorescent staining was made with monoclonal antibodies used to assess antigen coexpression on single cell membranes. Analysis of data used FCS 3 software.

Disease stage was assessed basing on the Ann-Arbor (1971) staging supplemented by Cotswald (1989).

Treatment principally included either chemotherapy (CHOP or CVP) or/after 2000/the same protocols with rituximab. These changes in treatment protocols did not effect the collected data, the prognostic value of CD23 FDC was the same.

Assessment of immediate and follow-up response to therapy was made according to international standardized response criteria in non-Hodgkin's lymphoma [4].

Assessment of follow up results was made using Kaplan-Meier (1958) curves that reflected cumulative survival by the beginning of certain time intervals.

Progression-Free Survival (PFS) was defined as time from start of therapy or watchful waiting till disease progression or recurrence or last patient's visit.

Overall Survival (OS) was defined as time from treatment start till the date of patient's death from any cause or last visit. 
Statistical analysis of study results included comparison of means, non-parametric data were analyzed using contingency tables and Pearson's chi squared test (1990). Significance of the effect of prognostic factors on patients' survival and response duration was ere assessed using Cox regression.

\section{Results}

Immunohistochemical identification of CD23+ FDCs in FL tissue was made in 232 patients with $87.5 \%$ of positive tests (Table 1 ).

The positive tests included all cases with tumor tissue FDCs as areas of hyperplasia, loose areas and remaining groups of FDCs.

Since CD23 is used to identify FDCs of follicular clear centers, it was not unexpected to find that the presence of CD23+ FDCs correlated highly with nodular growth pattern in FL, $\mathrm{p}=0.000$ (Table 2).

CD23+ FDCs were found in next to $100 \%$ of tumors with nodular growth against $58.3 \%$ of those with diffuse growth.

The presence of CD23+ FDCs was found not related with FL cytology ( $\mathrm{p}=$ 0.45).

There was no association between CD23+ FDCs and clinical prognostic factors such as patient age above 60 years $(\mathrm{p}=0.2)$, the number of FLIPI poor prognosis criteria $(\mathrm{p}=0.72)$, FLIPI risk groups $(\mathrm{p}=0.9)$, IPI prognostic factors $(\mathrm{p}=0.77)$ or IPI risk groups $(\mathrm{p}=0.55)$.

Disease stage was not associated with the presence of CD23+ FDCs either $(\mathrm{p}=$ $0.55)$.

We failed to find association with ECOG performance status $(p=0.37$ ), intoxication symptoms $(\mathrm{p}=0.7)$ or elevated Lactat Dehydrogenase $(\mathrm{LDH})$ levels $(\mathrm{p}=$ $0.73)$.

Table 1. CD23+ FDCs frequency in FL tissue.

\begin{tabular}{ccc}
\hline CD23+ FDCs & Frequency & Percent \\
\hline Absent & 29 & 12.5 \\
Present & 203 & 87.5 \\
Total & 232 & 100.0 \\
\hline
\end{tabular}

Table 2. Relation of CD23+ FDCs with cell growth pattern in FL.

\begin{tabular}{ccccc}
\hline \multirow{2}{*}{ Growth pattern } & \multicolumn{2}{c}{ CD23+ FDCs } & \multirow{2}{*}{ Total } \\
\cline { 2 - 3 } & Frequency & yes & no & \\
Nodular & $\%$ & 3 & 81 & 84 \\
& Frequency & $3.6 \%$ & $96.4 \%$ & $100.0 \%$ \\
Nodular-diffuse & $\%$ & 2 & 61 & 63 \\
Diffuse-nodular & Frequency & $3.2 \%$ & $96.8 \%$ & $100.0 \%$ \\
& $\%$ & 4 & 31 & 35 \\
Diffuse & Frequency & $11.4 \%$ & $88.6 \%$ & $100.0 \%$ \\
& $\%$ & 10 & 14 & 24 \\
& & $41.7 \%$ & $58.3 \%$ & $100.0 \%$ \\
\hline
\end{tabular}


Hematology parameters such as hemoglobin $(\mathrm{p}=0.6)$, red cell $(\mathrm{p}=0.46)$ levels, MCV $(\mathrm{p}=0.11)$ or MCHC $(\mathrm{p}=0.13)$ were not associated with CD23+ FDCs status in FL tissue. One exception was mean platelet volume (MPV, p = 0.023; Table 3).

As seen, CD23+ FDCs were detected in the tumor tissue considerably less frequently in patients with decreased MPV.

Hematology parameters such as levels of platelets $(\mathrm{p}=0.68)$, leukocytes $(\mathrm{p}=$ $0.25)$, monocytes $(p=0.95)$, neutrophils $(p=0.41)$, lymphocytes $(p=0.94)$ were not associated with the presence of CD23+ FDCs in the tumor tissue of FL patients.

Serum total protein $(\mathrm{p}=0.67)$ and albumin $(\mathrm{p}=0.058)$ demonstrated no significant relationship with tumor microenvironment, i.e. CD23+ FDCs.

Among clinical characteristics associated with lymph node involvement, position and extramedullary disease it was only the presence of disease sites below the diaphragm that demonstrated relation with the presence of CD23+ FDCs in lymphoid tissue (Table 4).

Disease in the liver $(\mathrm{p}=0.72)$, spleen $(0.59)$, more than one extranodal site $(\mathrm{p}=$ 0.19 ) had no association with the presence of FDCs in the tumor (CD23+).

The presence of CD23+ FDCs showed no relationship with bone marrow involvement in FL by histology $(\mathrm{p}=0.55)$.

Among bone marrow lymphocyte subsets only CD10+ CD23+ B-lymphocytes were significantly higher in CD23+ FDCs patients: $38.3 \% \pm 8.5 \%(n=17)$ and $11.7 \% \pm 6.1 \%(\mathrm{n}=5), \mathrm{p}=0.021$.

The presence of FDCs (CD23+) in FL tissue was associated with both immediate and follow-up treatment results (Table 5, Figure 1 and Figure 2).

Table 3. CD23+ FDCs frequency in patients with different platelet volumes (MPV).

\begin{tabular}{|c|c|c|c|c|}
\hline \multirow{2}{*}{\multicolumn{2}{|c|}{ MPV }} & \multicolumn{2}{|c|}{ CD23+ FDCs } & \multirow{2}{*}{ Total } \\
\hline & & no & yes & \\
\hline \multirow{2}{*}{ Normal } & Frequency & 16 & 152 & 168 \\
\hline & $\%$ & $9.5 \%$ & $90.0 \%$ & $100.0 \%$ \\
\hline \multirow{2}{*}{ Decreased } & Frequency & 5 & 11 & 16 \\
\hline & $\%$ & $31.3 \%$ & $68.8 \%$ & $100.0 \%$ \\
\hline \multirow{2}{*}{ Increased } & Frequency & 1 & 16 & 17 \\
\hline & $\%$ & $5.9 \%$ & $94.1 \%$ & $100.0 \%$ \\
\hline
\end{tabular}

Table 4. CD23+ FDCs are more frequently found in the tumor tissue from patients with disease sites below the diaphragm $(\mathrm{p}=0.04)$.

\begin{tabular}{|c|c|c|c|c|}
\hline \multirow{2}{*}{\multicolumn{2}{|c|}{ Disease sites below the diaphragm }} & \multicolumn{2}{|c|}{ CD23+ FDCs } & \multirow{2}{*}{ Total } \\
\hline & & no & yes & \\
\hline \multirow{2}{*}{ No } & Frequency & 17 & 77 & 94 \\
\hline & $\%$ & $18.1 \%$ & $81.9 \%$ & $100.0 \%$ \\
\hline \multirow{2}{*}{ Yes } & Frequency & 12 & 123 & 135 \\
\hline & $\%$ & $8.9 \%$ & $91.1 \%$ & $100.0 \%$ \\
\hline
\end{tabular}


Table 5. Association between FDCs (CD23+) in the tumor tissue and immediate treatment results.

\begin{tabular}{|c|c|c|c|c|}
\hline \multicolumn{2}{|c|}{ Treatment result } & \multicolumn{2}{|c|}{ CD23+ FDCs } & \multirow{3}{*}{$\begin{array}{c}\text { Total } \\
20\end{array}$} \\
\hline & & \multirow{2}{*}{$\begin{array}{c}\text { no } \\
0\end{array}$} & \multirow{2}{*}{$\begin{array}{c}\text { yes } \\
20\end{array}$} & \\
\hline Complete & Frequency & & & \\
\hline response & $\%$ & $0 \%$ & $100.0 \%$ & $100.0 \%$ \\
\hline \multirow{2}{*}{ Partial response } & Frequency & 2 & 5 & 7 \\
\hline & $\%$ & $28.6 \%$ & $71.4 \%$ & $100.0 \%$ \\
\hline \multirow{2}{*}{ Stable disease } & Frequency & 0 & 2 & 2 \\
\hline & $\%$ & $0 \%$ & $100.0 \%$ & $100.0 \%$ \\
\hline Progressive & Frequency & 2 & 3 & 5 \\
\hline disease & $\%$ & $40.0 \%$ & $60.0 \%$ & $100.0 \%$ \\
\hline
\end{tabular}

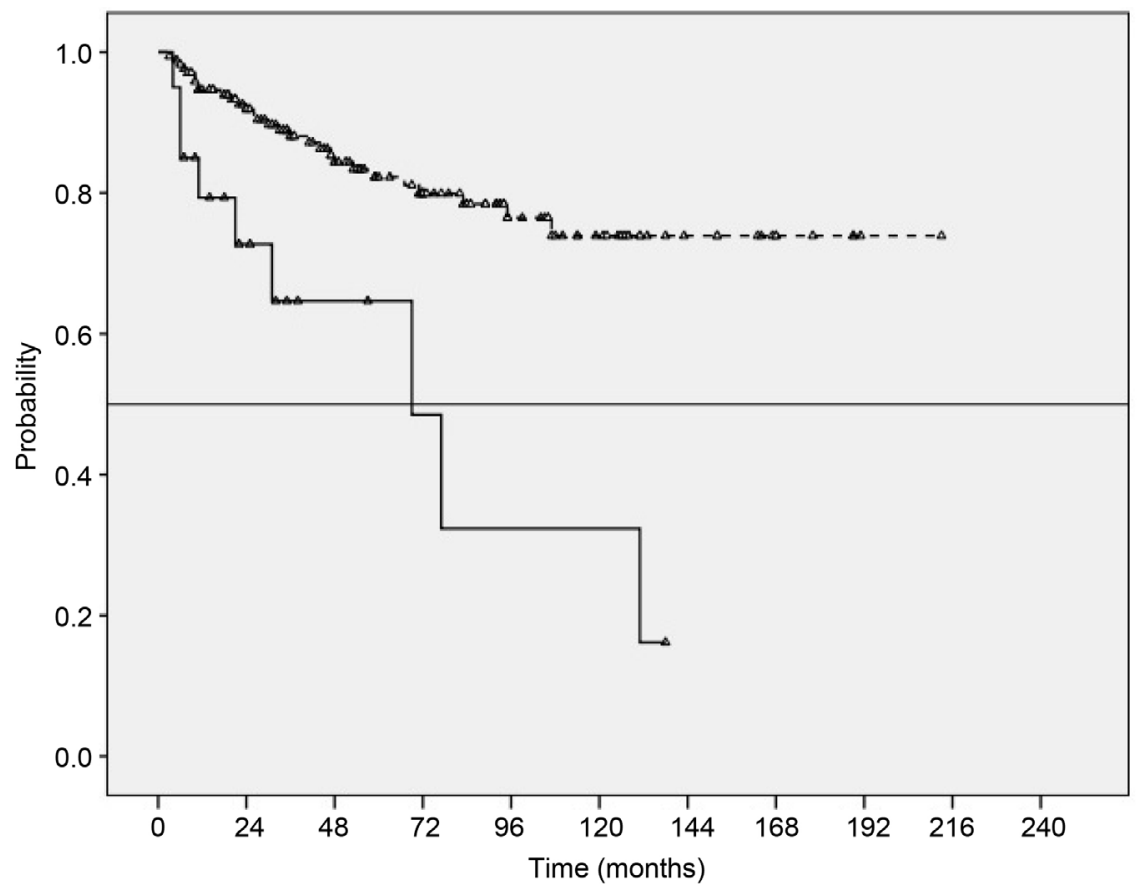

Figure 1. OS of FL patients with respect to the presence of CD23+ FDCs in the tumor tissue (upper curve: CD23+ FDCs present, $\mathrm{n}=172$; lower curve: $\mathrm{CD} 23+$ FDCs absent, $\mathrm{n}=$ 20).

As seen, CD23+ FDCs were found in the tumor tissue in $100 \%$ of the largest group (20 patients) achieving complete response CR $(\mathrm{p}=0.034)$.

It is of most importance that the presence of CD23+ FDCs in the tumor tissue was associated with prognosis in FL.

Analysis of OS demonstrated that patients with CD23+ FDCs lived significantly longer than those free from CD23+ FDCs $(p=0.000$; Figure 1).

Basing on these findings the conclusion may be made that the presence of FDCs (CD23+) in the tumor tissue is an important factor of good prognosis in FL.

However, if hematogenic dissemination occurs as most fully reflected by bone 


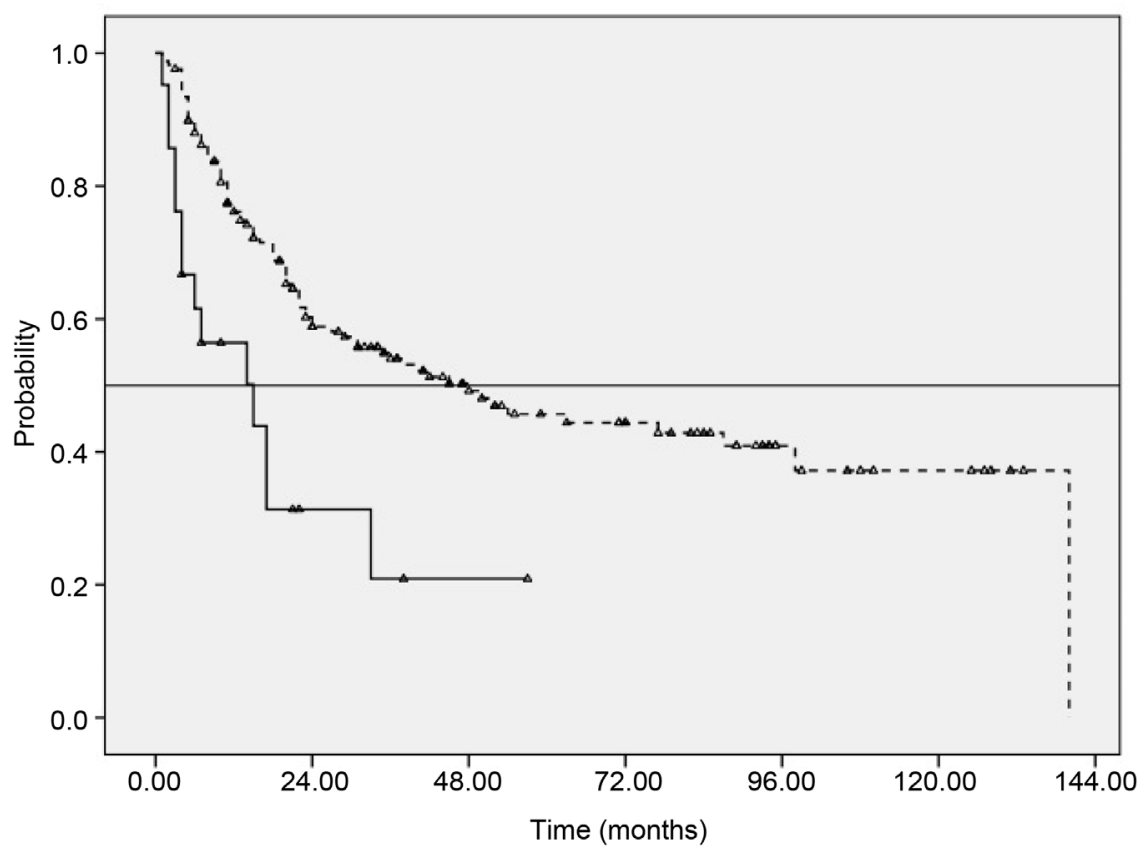

Figure 2. PFS with respect to the presence of CD23+ FDCs in the tumor tissue (upper curve: CD23+ FDCs present, $\mathrm{n}=168$; lower curve: CD23+ FDCs absent, $\mathrm{n}=21$ ).

marrow involvement, the prognosis worsens dramatically. Bone marrow involvement and the presence of CD23+ FDCs in the tumor tissue are not at all mutually exclusive characteristics of FL. In our population of 230 patients in whom analysis of tumor FDCs and bone marrow was performed no direct correlation between these characteristics was found ( $p>0.05) .85$ of 201 (42.3\%) patients presented with both CD23+ FDCs in the tumor tissue and bone marrow involvement (Table 6).

Basing on the presence of CD23+ FDCs in tumor sections and bone marrow involvement we distinguished 3 groups of FL patients:

1) $\mathrm{CD} 23+$ FDCs present, no bone marrow involvement;

2) $\mathrm{CD} 23+\mathrm{FDCs}$ present, bone marrow involvement;

3) $\mathrm{CD} 23+$ FDCs absent.

It seems reasonable to compare survival data first of all in patients having CD23+ FDCs in the tumor sections with and without bone marrow involvement: differences between these groups were highly significant $(p=0.001$; Figure 3$)$.

There were 15 patients with CD23 FDCs- status, and as seen from Figure 4, they composed the poorest prognosis group. Differences in survival between the three groups were highly significant $(p=0.000)$.

As demonstrated by our findings, an additional prognostic index based on immunomorphology of the primary tumor and bone marrow may be useful together with FLIPI. Basing on this index (FDCs IPI) patients with CD23+ FDCs in tumor sections should be included into a good prognosis group, while those free from this cell type in their tumors should be referred to a poor prognosis group. Patients with bone marrow involvement should be distinguished in the good prognosis group as an intermediate prognosis subgroup. 
Table 6. Correlation between the presence of CD23+ FDCs in the tumor tissue and bone marrow involvement.

\begin{tabular}{ccccc}
\hline \multirow{2}{*}{ CD23+ FDCs } & \multicolumn{2}{c}{ Bone marrow involvement } & \multirow{2}{*}{ Total } \\
\cline { 3 - 4 } & & no & yes & \\
\hline \multirow{3}{*}{ Absent } & Frequency & 19 & 10 & 29 \\
& $\%$ & $65.5 \%$ & $34.5 \%$ & $100.0 \%$ \\
\multirow{3}{*}{ Present } & Frequency & 116 & 85 & 201 \\
& $\%$ & $57.7 \%$ & $42.3 \%$ & $100.0 \%$ \\
\hline
\end{tabular}

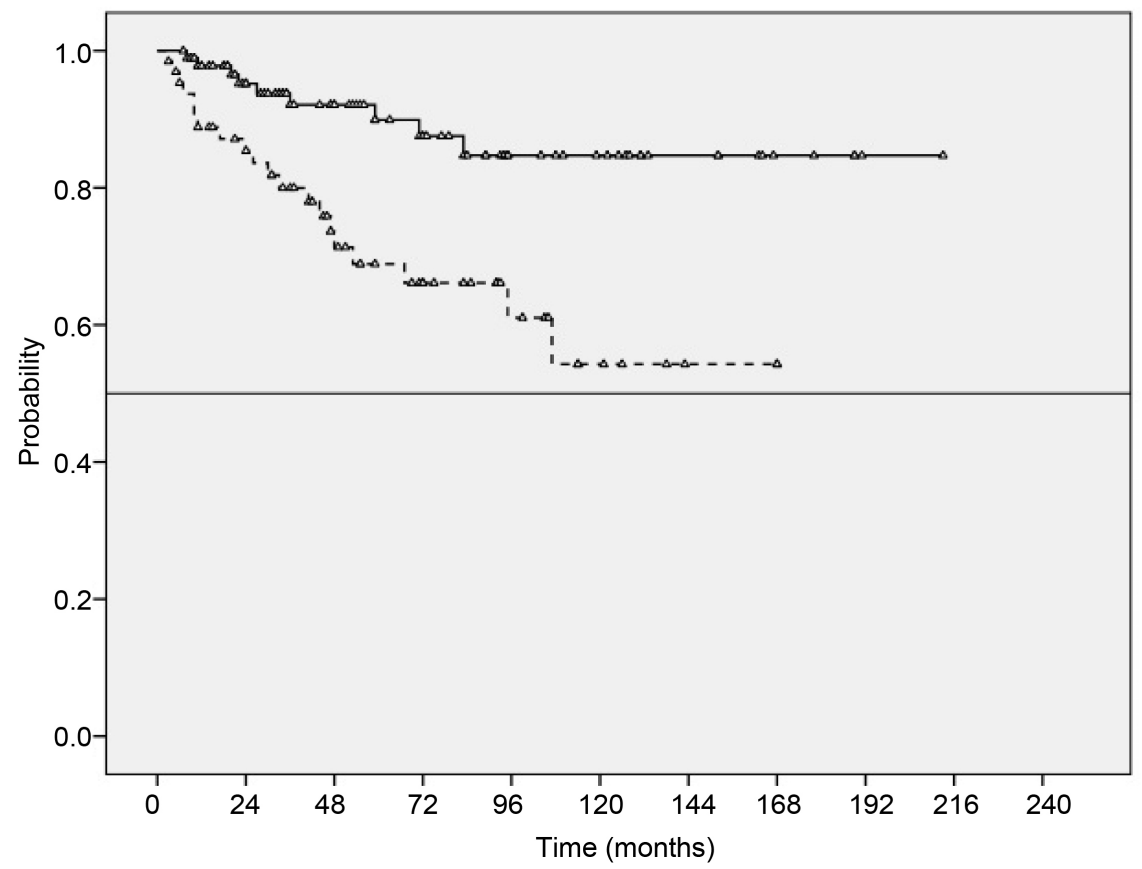

Figure 3. OS in FL patients with positive status of tumor CD23+ FDCs with respect to bone marrow involvement (upper curve: no involvement, $\mathrm{n}=94$; lower curve: involvement, $\mathrm{n}=65$ ).

As seen in Figure 5, this index helps to successfully stratify patients into risk groups basing on analysis of PFS $(\mathrm{p}=0.000)$. It should be noted however that PFS worsens considerably in the presence of bone marrow involvement even in CD23+ FDCs+ cases.

So, absolute majority of FL patients (87.5\%) have FDCs (CD23+) in the tumor tissue. This characteristic in itself is indicative of nodular growth and shows a high correlation with growth pattern (nodularity) as determined morphologically. The presence of CD23+ FDCs is not related to any of the FLIPI or IPI prognostic factors. This characteristic is less common in patients with decreased MPV, but is encountered more frequently in cases with lymphoma sites below the diaphragm.

Patients with CD23+ FDCs+ FL have a good prognosis as demonstrated basing on immediate treatment results, PFS and OS. It should be noted that nodular growth which correlated with the presence of $\mathrm{CD} 23+\mathrm{FDCs}$ in tumors showed relationship with OS but not with PFS. 


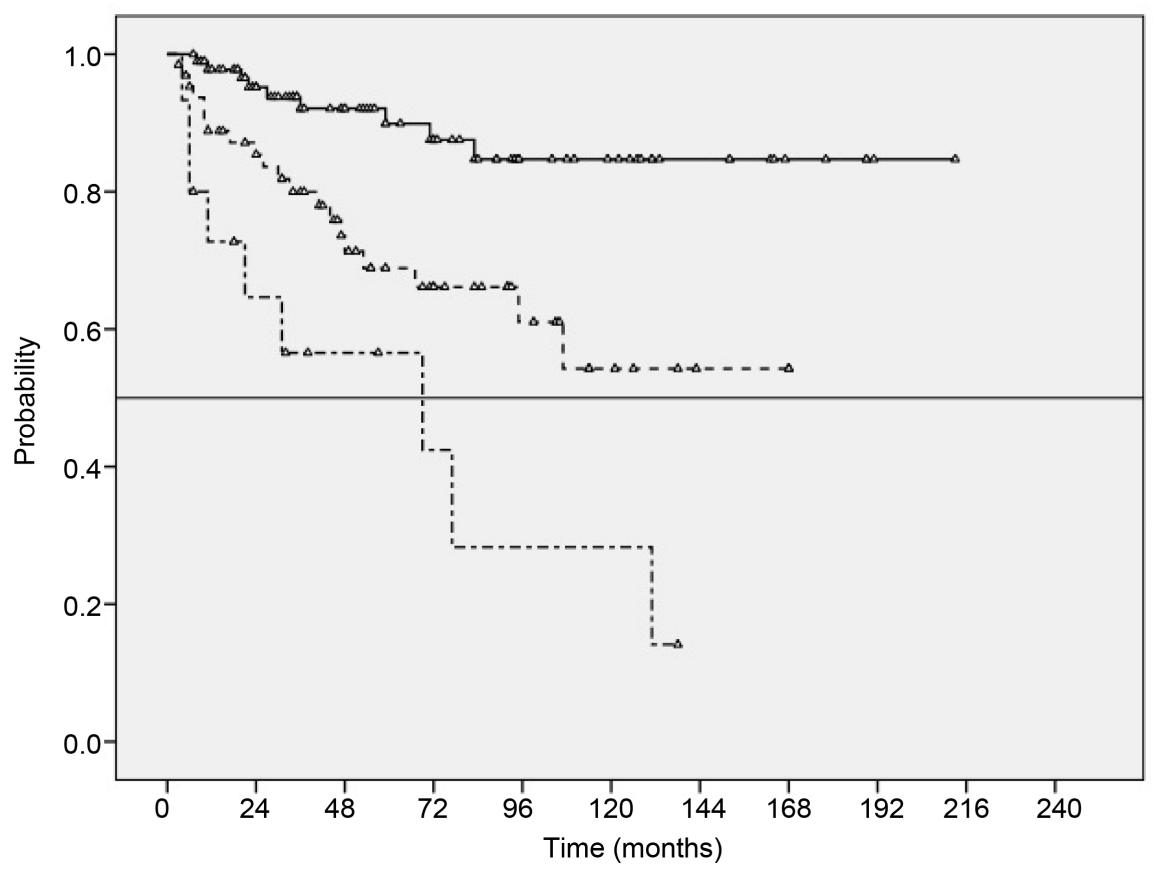

Figure 4. OS in FL patients from three prognostic groups: CD23+ BM- (upper curve), $\mathrm{CD} 23+\mathrm{BM}+$ (middle curve), $\mathrm{CD} 23-\mathrm{BM} \pm$ (lower curve).

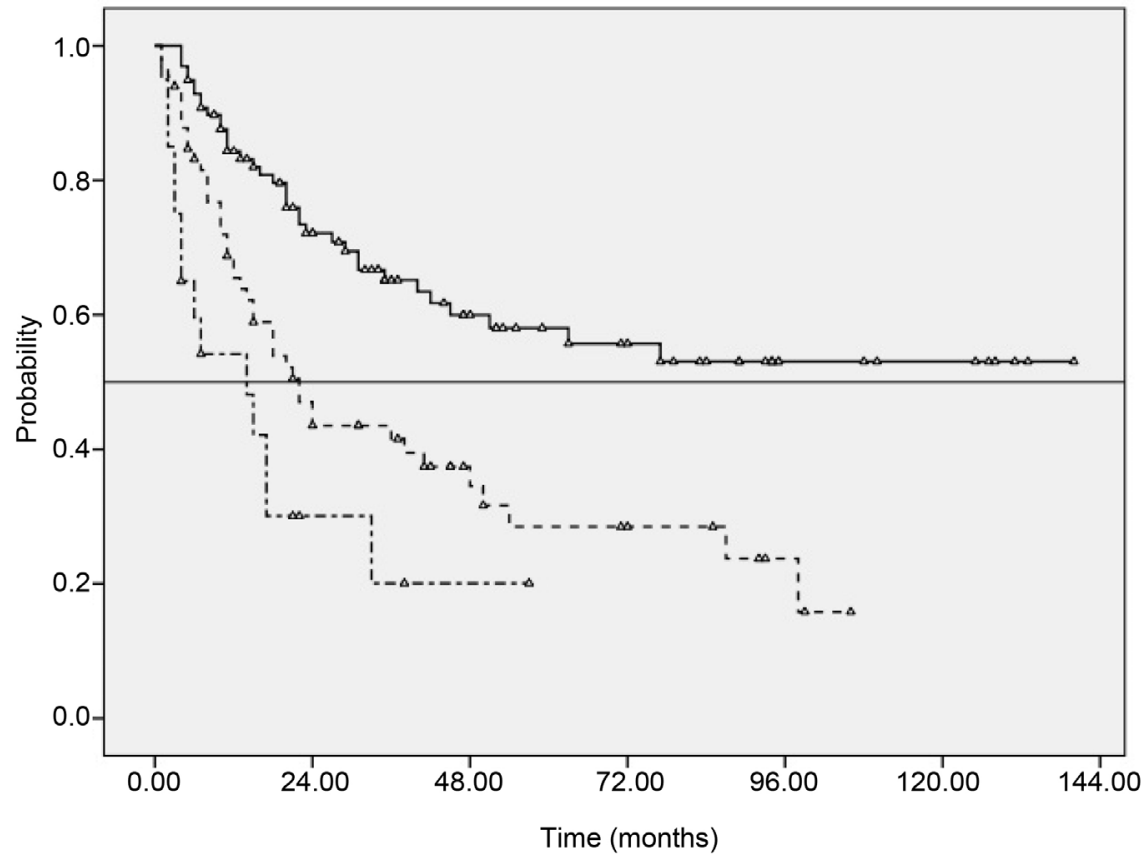

Figure 5. PFS in three patient groups: CD23+ BM- (upper curve, $\mathrm{n}=94$ ), CD23+ BM+ (middle curve, $\mathrm{n}=65), \mathrm{CD} 23-\mathrm{BM} \pm$ (lower curve, $\mathrm{n}=15$ ).

As demonstrated by multivariate analysis (Cox regression), the presence of CD23+ FDCs in the tumor tissue had significant independent value for OS ( $\mathrm{p}=$ $0.006)$ and PFS ( $\mathrm{p}=0.02)$.

CD23+ FDCs status in the tumor tissue was not associated with bone marrow involvement as detected by histology of trepan biopsies, however, bone marrow 
involvement worsened considerably the prognosis in CD23+ FDCs+ patients with FL.

\section{Discussion and Conclusion}

FL is a unique hematology malignancy. It stands by itself even among immunity tumors due to a number of specific properties and characteristics. This malignancy belongs to small-cell lymphomas, though its cellular substrate is highly heterogeneous. Besides centrocytes it always contains various proportions of centroblasts that are taken into account in the diagnosis (WHO, 2008). FL is a tumor that in its most typical variant always forms tissue structures similar in their composition to normal germinal centers of lymph node follicles. These follicular centers always include non-hemopoietic skeleton cells referred to as CD23+ FDCs.

As a rule FL demonstrates a nodular growth pattern, which means that lymph node structure at morphological level shows hyperplasic follicles with clear germinal centers.

FL belongs to good prognosis lymphomas. In its typical classical form the disease may last for years or decades even without specific treatment.

In spite of the vast evidence of FL pathogenetic specificity, there is no breakthrough in this area yet. The diagnosis is made using standard descriptive procedures and the prognosis is mainly based on disease advance.

The absence of the highly significant relationship between FL course and tumor substrate morphology by many characteristics has compelled us to a more detailed analysis of immunological characteristics of the primary tumor.

The presence of CD23+ FDCs is not related to any of FLIPI or IPI prognostic factors. This characteristic is less common in patients with decreased MPV and more frequently found in cases with lymphoma sites below the diaphragm.

FDCs status in the tumor tissue shows no association with bone marrow involvement as detected by bone marrow histology. It is of most importance that CD23+ FDCs in the tumor tissue had all signs of a factor of good prognosis as demonstrated by immediate treatment outcome, PFS and OS. Multivariate analysis demonstrated that the presence of CD23+ FDCs in the tumor tissue was the most significant independent factor of prognosis for OS and PFS. So, when analyzing clinical, hematological and biochemical prognostic factors we established an important prognostic role (good prognosis) of the presence of microenvironment component, i.e. $\mathrm{CD} 23+\mathrm{FDCs}$ in the primary tumor.

FDCs were described by the Russian scientist A. Maximov already in 1927 [5] as embryonic non-phagocyting reticular cells. Later these cells were described in 1965 by J. Mitchell and A. Abbott [6] as specific cells with filiform projects able to capture and hold antigens in secondary lymphoid organs. However, understanding of their role in normal lymphocyte differentiation and pathogenetic role in $\mathrm{FL}$ is far from being complete.

Development of secondary immune response in lymph nodes with emerging clear centers is always accompanied by the appearance of a certain skeleton for 
cells of the follicular center composed by $\mathrm{CD} 23+$ dendritic cells. This rule has no exceptions. This non-hemopoietic component of the secondary immune response is mandatory for adequate selection of specific high-affinity B-cell clones after passing the stage of somatic mutation.

However, the role of the clear center skeleton, i.e. FDCs (CD23+) in FL is not fully understood. In the WHO (2008) classification [3] they are mentioned as concerns in the primary diagnosis of FL only as indication of lymphoma nodular growth pattern. Current knowledge about FDCs provides convincing evidence that this is not the only role of FDCs, and their contribution to FL pathogenesis may be of critical importance.

Recent study data confirm most convincingly that FDCs may originate from bone marrow stromal progenitors [7]. These studies also confirm findings of earlier experimental investigations [8]. FDCs emerge in bone marrow from STRO-1+ bone marrow cells forming fibroblast colonies and are similar or identical to mesenchymal stem cells. These progenitors migrate from the bone marrow into secondary lymphoid organs and differentiate into certain lineages. Some authors believe FDCs to play the central role in lymphoid tissues [9].

In order to better understand the role of CD23+ FDCs, one has to consider processes occurring in germinal centers of lymph node follicles. Microenvironment of germinal centers is the place where a multi-step process of B-cell maturation and differentiation occurs that leads to generation of plasmatic cells and memory B-lymphocytes. There are a great variety of interactions between B-cells, antigens, T-cells, macrophages and FDCs within the clear follicular centers.

The basement (or dark) area of the germinal center is the place where activated B-lymphocytes loose $\mathrm{CD} 23$ and turn into large blast forms (centroblasts) to that proliferate actively. The centroblasts are characterized by expression of CD77, CD38, no IgD, practically no IgM, decreased levels of CD44 and L-selectins. Most of these cells die by apoptosis because the anti-apoptotic gene bcl-2 does not work in centroblasts.

The cell debris is engulfed by germinal center macrophages referred to as tingible-body macrophages. Surviving cells reduce in size, their nuclei shrink and look split (centrocytes). Membrane Igs appear on the centrocytes again. These lymphoid elements have already passed the stage of isotypic switch and express IgG, IgA or IgE. As a result of somatic hypermutation the centrocytes acquire high affinity to antigens. They express CD23. A part of germinal center cells express CD10, activating antigens CD25, CD71, etc. The centrocytes originate memory B-cells and plasmatic cells. This occurs at the apical clear zone of follicular germinal centers heavily populated with FDCs. The FDCs bear a large amount of the antigen to which the response is formed in this very germinal center. The antigen on the surface of FDCs is retained in the form of immune complexes with antibodies and complement. This is because FDCs express a broad range of Fc-receptors (CD23-FceRII, CD16-Fc $\gamma$ IIIR, CD32-Fc $\gamma$ IIR) and complement receptors (CD35-CR1, CD21-CR2, CD11b-C3biR). The antigen on 
FDCs surface is presented to B-cells in the free form or in the form of antigen-loaded small membrane bodies referred to as "icosomes". A subset of intrafollicular T-helpers with phenotype CD4+ CD45RO+ CD57+ play an important role: their absence makes impossible formation of germinal centers, isotypic switch or generation of memory B-cells.

B-lymphocyte differentiation into either memory cells or plasmocytes is regulated at the apical clear zone of germinal centers. Binding of B-lymphocyte molecule CD40 to CD40L present at activated T-cells leads to generation of memory B-cells. Plasmocytic differentiation of B-cells occurs after their interaction with CD23 soluble fragment or with antigen CD23 present on FDCs. These interactions involve receptor of CD21 and IL-1.

Basing on experimental studies [10] the following FDCs' functions may be summarized:

- Organization of lymphoid microarchitecture. FDCs play the key role in compartmentation of various cell types in lymphoid follicles [11] [12].

- Antigen capture and retaining. FDCs possess the unique ability to retain immune complexes on their tree-like projects for a long time. In fact it was the retaining of injected labeled antigens that allowed detection of these cells. This gave rise to a 10-year discussion of the role of this phenomenon in generation of adaptive immune responses: whether the chronic antigen retaining may promote generation of long-term immunological memory.

- Organization of debris scavenging. Clear center B-cells undergo selection after hypermutation of IgV genes. Cells that demonstrate no specificity to the antigen retaining on FDCs or clear center microenvironment undergo apoptosis. The second stage of this selection removes autoreactive cells, and again unable B-cells undergo apoptosis. Lymphoid follicles are therefore characterized by a very high rate of cell deathying. Scavenging of the dead cells is effected by special tingible-body macrophages called so after intensely colored apoptotic debris in the cytoplasm. However these macrophages are not numerous and are found remotely from each other which makes difficult adequate follicle scavenging. FDCs secretory factor Mfge8 which cross-links with apoptotic cells and phagocytes. FDCs thus help to selectively remove debris in places of B-cell most active dying [12].

- Autoimmunity prevention. As shown in experiments on mice, the absence of Mfge8 is associated with a disease in many respects similar to systemic lupus erythematosus. These findings suggest FDCs to play a role in prevention of autoimmune reactions. In the absence of Mfge8, TBMj demonstrated reduced engulfing of dead cells. FDCs therefore possess the important ability to protect the body from autoimmune reactions through accelerated removal of potentially immunogenic debris of its own cells from clear centers of lymph node follicles.

It is absolutely clear that organization of lymphoid microarchitecture is the most attractive FDCs' function as concerns FL. The presence of CD23+ FDCs in the tumor tissue is a reflection of tumor structural organization. In these cases 
structural atypia is either undetectable or minimally detectable. It follows therefore that cases with FDCs present in the tumor tissue may be considered as manifestations of early disease stages at which lymphoma preserves normal tissue structure of lymph node germinal centers. At the tissue level this corresponds to lymphoma nodular growth pattern. However, this nodularity is not always detectable at the morphological level, and additional detection of the FDCs criterion allows a more accurate identification of structural organization within the tumor. Importantly, the presence of FDCs in the tumor tissue is evidence of formation and functioning of follicular germinal centers. FDCs interaction with centroblasts and centrocytes is very strong: these cells cannot be disconnected even in vitro, and to study FDCs properties adequately one has to wait till B-cells die in vitro. In fact these interactions serve as a mechanism of retaining malignant cells from clear centers on the FDCs project skeleton. In normal immune response this is the mechanism of selection of most specific and elimination of less specific clones and autoimmune cells. As concerns tumor growth, this property presents a certain antimetastatic mechanism. Even in cases with a rather considerable spread of FL along the lymphatic system the FDCs presence in the tumor tissue is indicative of disease partially or fully localized within clear centers. In other words, basing on immunomorphological detection of CD23+ FDCs in the tumor tissue one can identify an earlier phase of FL growth, i.e. the phase of tumor dissemination control through retaining malignant lymphoid cells by FDCs within lymphatic system germinal centers.

It was reasonable therefore to use this characteristic as the principal immunomorphological prognostic factor in multivariate analysis of FL patients in our study. It is evident that in a proportion of patients with FL spreading over the lymphatic system the disease may be defined as conditionally localized within each lymph node zone. FL cases with CD23+ FDCs in the tumor tissue may be referred to the phase of immunological and molecular control of lymphoma advance through retaining of malignant cells in lymph node follicles.

Such interpretation of data fully corresponds to the current staging and prognosis policy in FL including assessment of tumor spread over the lymphatic system, and supplements it with findings about local control of FL cell dissemi-nation.

Our data demonstrate that an additional prognostic index may be used together with FLIPI that is based on immunomorphology of the primary tumor and bone marrow. According to this index (FDCs IPI) patients with CD23+ FDCs+ tumor sections may be referred to a good prognosis group while patients free from this cell type in the tumor belong to a poor prognosis group. It seems reasonable to distinguish an intermediate prognosis subgroup, i.e. patients with bone marrow involvement within the good prognosis group.

In conclusion, we were the first to establish the role of cells from non-tumor environment, i.e. $\mathrm{CD} 23$ (FcelIR)-positive FDCs, in the diagnosis of FL, and to assess their detection in connection with clinical, morphological and prognostic parameters. The receptor (CD23) allowed identification of FDCs in follicular 
centers of malignant lymph node follicles in $87 \%$ of FL cases and was is the only significant independent immunomorphological characteristic by multivariate analysis: cases free from CD23+ FDCs had poor prognosis.

So, the immunomorphological characteristic with a well known functional role receptor may be added to the FLIPI prognostic factors, which are listed in recent ESMO guidelines [13].

\section{References}

[1] Solal-Céligny, P., Roy, P., Colombat, P., White, J., Armitage, J.O., Arranz-Saez, R., Au, W.Y., Bellei, M., Brice, P., Caballero, D., Coiffier, B., Conde-Garcia, E., Doyen, C., Federico, M., Fisher, R.I., Garcia-Conde, J.F., Guglielmi, C., Hagenbeek, A., Haïoun, C., LeBlanc, M., Lister, A.T., Lopez-Guillermo, A., McLaughlin, P., Milpied, N., More,l P., Mounier, N., Proctor, S.J., Rohatiner, A., Smith, P., Soubeyran, P., Tilly, H., Vitolo, U., Zinzani, P.L., Zucca, E. and Montserrat, E. (2004) Follicular Lymphoma International Index. Blood, 104, 1258-1265.

https://doi.org/10.1182/blood-2003-12-4434

[2] Dave, S.S., Wright, G., Tan, B., Rosenwald, A., Gascoyne, R.D., Chan, W.C., Fisher, R.I., Braziel, R.M., Rimsza, L.M., Grogan, T.M., Miller, T.P., LeBlanc, M., Greiner, T.C., Weisenburger, D.D., Lynch, J.C., Vose, J., Armitage, J.O., Smeland, E.B., Kvaloy, S., Holte, H., Delabie, J., Connors, J.M., Lansdorp, P.M., Ouyang, Q., Lister, T.A., Davies, A.J., Norton, A.J., Muller-Hermelink, H.K., Ott, G., Campo, E., Montserrat, E., Wilson, W.H., Jaffe, E.S., Simon, R., Yang, L., Powell, J., Zhao, H., Goldschmidt, N., Chiorazzi, M. and Staudt, L.M. (2004) Prediction of Survival in Follicular Lymphoma Based on Molecular Features of Tumor-Infiltrating Immune Cells. The New England Journal of Medicine, 351, 2159-2169. https://doi.org/10.1056/NEJMoa041869

[3] Swerdlow, S.H., Campo, E., Harris, N.L., et al. (2008) WHO Classification of Tumours of Haematopoietic and Lymphoid Tissues. 4th Edition, IARC Press, Lyon, 220-226.

[4] Cheson, B.D., Horning, S.J., Coiffier, B., Shipp, M.A., Fisher, R.I., Connors, J.M., Lister, T.A., Vose, J., Grillo-López, A., Hagenbeek, A., Cabanillas, F., Klippensten, D., Hiddemann, W., Castellino, R., Harris, N.L., Armitage, J.O., Carter, W., Hoppe, R. and Canellos, G.P. (2000) Report of an International Workshop to Standardize Response Criteria for Non-Hodgkin's Lymphomas. NCI Sponsored International Working Group. Journal of Clinical Oncology, 17, 1244.

https://doi.org/10.1200/JCO.1999.17.4.1244

[5] Maximow, A. (1927) Bindegewebe und blutbildende Gewebe. In: Von Mollendorf, W., Ed., Handbuch der normalen mikroskopischen Anatomie des Menschen, Springer, Berlin, Bd. II/I, 232-583. https://doi.org/10.1007/978-3-642-66441-0_2

[6] Mitchell, J. (1965) Ultra Structure of the Antigen-Retaining Reticulum of Lymph Node Follicles as Shown by High-Resolution Autoradiography. Nature, 30, 500-502. https://doi.org/10.1038/208500b0

[7] Muñoz-Fernández, R., Blanco, F.J., Frecha, C., Martín, F., Kimatrai, M., Abadía-Molina, A.C., García-Pacheco, J.M. and Olivares, E.G. (2006) Follicular Dendritic Cells Are Related to Bone Marrow Stromal Cell Progenitors and Myofibroblasts. The Journal of Immunology, 177, 280-289. https://doi.org/10.4049/jimmunol.177.1.280

[8] Kapasi, Z.F., Qin, D., Kerr, W.G., Kosco-Vilbois, M.H., Shultz, L.D., Tew, J.G. and Szakal, A.K. (1998) Follicular Dendritic Cell (FDC) Precursors in Primary Lymphoid Tissues. The Journal of Immunology, 160, 1078-1084. 
[9] Schriever, F. and Nadler, L.M. (1992) The Central Role of Follicular Dendritic Cells in Lymphoid Tissues. Advances in Immunology, 51, 243-284.

[10] Aguzzi, A. and Krautler, R.J. (2010) Characterizing Follicular Dendritic Cells: A Progress Report. European Journal of Immunology, 40, 2134-2138. https://doi.org/10.1002/eji.201040765

[11] Mackay, F. and Browning, J.L. (395) Turning off Follicular Dendritic Cells. Nature, 395, 26-27. https://doi.org/10.1038/25630

[12] Hanayama, R., Tanaka, M., Miyasaka, K., Aozasa, K., Koike, M., Uchiyama, Y. and Nagata, S. (2004) Autoimmune Disease and Impaired Uptake of Apoptotic Cells in MFG-E8-Deficient Mice. Science, 304, 1147-1150.

https://doi.org/10.1126/science.1094359

[13] Dreyling, M., Ghielmini, M., Marcus, R., Salles, G., Vitolo, U., Ladetto, M. and ESMO Guidelines Working Group (2014) Newly Diagnosed and Relapsed Follicular Lymphoma: ESMO Clinical Practical Guidelines for Diagnosis, Treatment and Follow up. Annals of Oncology, 25, 76-82. https://doi.org/10.1093/annonc/mdu200

\section{Submit or recommend next manuscript to SCIRP and we will provide best} service for you:

Accepting pre-submission inquiries through Email, Facebook, LinkedIn, Twitter, etc. A wide selection of journals (inclusive of 9 subjects, more than 200 journals)

Providing 24-hour high-quality service

User-friendly online submission system

Fair and swift peer-review system

Efficient typesetting and proofreading procedure

Display of the result of downloads and visits, as well as the number of cited articles

Maximum dissemination of your research work

Submit your manuscript at: http://papersubmission.scirp.org/

Or contact abc@scirp.org 